\title{
Erratum to: gender-specific linkages of parents' childhood physical abuse and neglect with children's problem behaviour: evidence from Japan
}

Takashi Oshio $^{1 *}$ and Maki Umeda ${ }^{2}$

\section{Erratum}

After publication of the article [1], it has been brought to our attention that the information given regarding the availability of data and materials is incorrect. The section should read "The use of J-SHINE data is to be approved by the data control committee of the J-SHINE researcher group by request".

\footnotetext{
Author details

${ }^{1}$ Institute of Economic Research, Hitotsubashi University, 2-1 Naka, Kunitachi-shi, Tokyo 186-8603, Japan. ${ }^{2}$ Graduate School of Nursing Science, St. Luke's International University, 10-1 Akashi-cho, Chuo-ku, Tokyo 104-0044, Japan.
}

Received: 5 July 2017 Accepted: 6 July 2017

Published online: 12 July 2017

\section{Reference}

1. Oshio T, Umeda M. Gender-specific linkages of parents' childhood physical abuse and neglect with children's problem behaviour: evidence from Japan. BMC Public Health. 2016;16:1. doi:10.1186/s12889-016-3072-3.

\footnotetext{
* Correspondence: oshio@ier.hit-u.ac.jp 